\title{
A LIRA E SUA SOMBRA: \\ (DES) CONSTRUÇÕES DA IMAGEM POÉTICA NA LÍRICA DE MANUEL BANDEIRA
}

\section{Milton Rosendo Nascimento Júnior *}

\begin{abstract}
Resumo: Neste ensaio buscamos avaliar, na perspectiva da estrutura da lírica moderna, a desconstrução das formas convencionais de representação na poesia de Manuel Bandeira (1886-1968), isto é, de que modo a sua poética estaria mais intimamente ligada às profundas transformações promovidas pela reforma por que passaria a questão da mímesis na modernidade. Tencionamos investigar, no contexto da lírica bandeiriana, tanto a reapropriação das imagens da realidade previamente constituída quanto a ampliação semântica dessas imagens.
\end{abstract}

Palavras-chave: Desrealização, mímesis, modernismo, poesia.

\section{Decomposição e fantasia: as metas da metáfora}

De acordo com Friedrich (1991, p. 80) uma das principais contribuições de Arthur Rimbaud à poesia moderna é a chamada fantasia ditatorial, recurso estético que irá gerar uma supra-realidade mediante o emprego de contração, omissão, deslocação e recombinação das imagens do mundo real, ocasionando dessa maneira uma realidade que somente existe na língua. Através desse recurso, estava a poesia liberta dos limites impostos pela simples cópia dos conteúdos e imagens do mundo. O processo criativo passou então a desfigurar violentamente as formas fixas de representação. Manuel Bandeira, um dos principais ícones do modernismo brasileiro, atento ao legado transmitido por Rimbaud, também se aproveita das possibilidades de construção poética suscitadas pela fantasia ditatorial e produz uma poesia que redimensiona a percepção das coisas. Como exemplo, tomemos este poema, intitulado "O amor, a poesia, as viagens:"

\footnotetext{
Doutorando em Literatura Brasileira pelo Programa de Pós-Graduação em Letras e Lingüistica da Universidade Federal de Alagoas.
} 


\author{
Atirei um céu aberto \\ $\mathrm{Na}$ janela do meu bem: \\ Caí na Lapa - um deserto... \\ - Pará, capital Belém!...
}

(BANDEIRA, 1993, p. 151)

Podemos constatar na composição dessa singela quadra formada por versos heptassílabos um complexo jogo imagístico em que ocorre uma deformação da realidade: o sujeito eliptico do poema, contrariando a lógica, apodera-se de algo que o transcende ("céu aberto") e atira-o na janela de sua amada, como se a coisa lançada se tratasse de uma pequena prenda. Observamos, portanto, que o poeta hiperdimensiona a possibilidade de ação do sujeito ao mesmo tempo que faz contrair a imagem da realidade. A elaboração imagística do poema sugere uma realidade decomposta, não pertencente ao extrato das coisas concretas, mas àquele constituído pela linguagem.

A fantasia ditatorial age nos dois primeiros versos desse poemeto no sentido de imprimir uma sensação tátil, de objeto palpável a uma coisa pertencente ao âmbito da visualidade, isto é, o céu. Nos dois versos seguintes, constatamos uma nova desconfiguração no plano representacional: cai o sujeito na Lapa numa instantaneidade que só de modo extremamente sutil expressa a sua frustração com relação a seu amor ("um deserto"), assim sonegando inúmeros detalhes que para a poesia tornam-se desnecessários. O deslocamento da Lapa para Belém, num quase simultaneismo que lembra em muito Rimbaud, sugere a tendência à fuga do real que tanto marca a poesia de Bandeira. Há nesses dois últimos versos da quadra um apagamento da noção real de espacialidade, pois, dentro da imagem construida pela fantasia do autor, a distância é anulada pela precipitação em um mundo que já não mais pertence à realidade objetiva, mas tão somente ao sonho.

O deslocamento do plano amoroso dos dois primeiros versos para o não-lugar metafórico da segunda metade da quadra revela a frustração como ponto central de sua estrutura lógica. Recai bem a esse texto poético o que sentencia Candido, em prefácio à Bandeira (1993, p. 11): "A metáfora simboliza, portanto, uma frustração, o contraste existente entre aquilo que o poeta se propõe alcançar e aquilo que de fato acaba alcançando, a distância que vai da aspiração à realidade". 
A poesia de Manuel Bandeira, assim sendo, se elabora a partir da ruína de suas experiências no mundo para gerar através da palavra fortes imagens extraídas de sua subjetividade lírica. É, por exemplo, da desilusão amorosa resultante em "O amor, a poesia, as viagens" que o poeta constrói com extrema mestria e poder de síntese uma decomposição das sólidas estruturas do real.

A poesia sugerida no título desse poema apenas transparece, e de modo metafórico, por meio dessa fugacidade das coisas e pela virtualização da realidade. Nesse sentido, Bandeira cria uma poesia que ultrapassa a idéia de arte como cópia da realidade, pois extrapola a mera representação, produzindo com isso matéria poética que amplia as dimensões do real.

A modernidade em Manuel Bandeira nasce dessa atualização do possível, atrofiando as formas da realidade, ampliando as suas dimensões semânticas. A poesia bandeiriana não se amolda ao simples reflexo de um universo pré-constituído, mas extrapola-o, produzindo um universo dominado pelas abstrações sensíveis da linguagem. Tal aspecto dessa poesia caracteriza aquilo que Friedrich (1991, p. 79-80) denomina de irrealidade sensivel e sobre a qual explica o seguinte:

A substância da realidade deformada fala muito amiúde por meio de grupos de palavras, dos quais cada parte integrante tem uma qualidade sensivel. Todavia, tais grupos reúnem aquilo que é objetivamente inconciliável de um modo tão anormal que, das qualidades sensiveis, resulta uma imagem irreal. Trata-se sempre de imagens que se podem contemplar, mas são de tal forma que o olho humano nunca poderia encontrá-las. Superam de longe aquela liberdade que sempre foi possível à poesia, graças às forças metafóricas fundamentais da língua.

Desse modo, o poema de Bandeira cria uma cena inusitada para os nossos olhos ("Atirei um céu aberto"), uma imagem que fundamentalmente só é possivel através de um processo de desrealização do real, em que se substancializa uma irrealidade.

\section{A questão da mímesis em Manuel Bandeira}

Em sintonia com os avanços estéticos das vanguardas européias, a poética de Bandeira rompe com a pura representação de 
um universo previamente constituído para desenvolver uma arte que absorve a ação produtiva da natureza. Ao mesmo tempo em que esse autor discute a criação poética, o fazer literário, passa também a discutir certos aspectos do processo de representação imagística na poesia. Vejamos a seguir, através deste poema de nome "A realidade $\mathrm{e}$ a imagem", a tensão existente no plano da imagem poética e a produção de um mimema que dilata a significação de um dado aparentemente corriqueiro:

O arranha-céu sobe no ar puro lavado pela chuva

E desce refletido na poça de lama do pátio.

Entre a realidade e a imagem, no chão seco que as separa,

Quatro pombas passeiam.

(BANDEIRA, 1993, p. 200)

Podemos verificar que, nessa quadra constituída de versos livres, o poeta discute, de maneira indireta, a questão da representação poética. Já no título do poema, há a insinuação de um contraponto entre realidade sensível e a sua representação imagística, como numa espécie de disposição dos pares de uma relação dialética. Passemos agora à análise propriamente dita de seus versos: o arranha-céu (elemento textual que serve de metáfora para a realidade) interage com a ação do olhar do poeta, acompanhando-o de modo a parecer que, tomado de fôlego vital, pratica-a ("sobe" / "desce"), ou seja, o objeto absorve metaforicamente o movimento do olhar de seu observador.

Há na verticalidade imagística ascendente do primeiro verso uma distorção do real, sobretudo, nessa mescla entre o objeto avistado pelo olhar e a ação do olhar que o examina em sua extensão. Assim, o objeto observado, ou seja, o arranha-céu, aparenta "subir" no ar atmosférico após a passagem da chuva. Fato semelhante se dá no segundo verso, ainda no plano da verticalidade, mas $\mathrm{cm}$ direção contrária, isto é, em sentido descendentc. Nesse verso, o arranha-céu acompanha o movimento do olhar do poeta, apropria-se de seu movimento para baixo e, refletido na poça de lama do pátio, passa a ser uma outra coisa, distorcida pelo seu próprio reflexo.

A imagem refletida do arranha-céu na poça de lama do pátio não corresponde a uma cópia exata, mas a uma inversão de seu sentido original. Entre a imagem do arranha-céu e o seu reflexo 
n'água, há um chão seco que os separa, numa possível alusão ao lavor literário, ao trabalho árido com as palavras que esperam traduzir o mundo. E, finalmente, no último verso, há um deslocamento da lente da representação para um novo e inesperado foco: quatro pombas a passear pelo chão. Com isso, o poeta demonstra que entre o objeto motivador da poesia (realidade) e a sua representação por meio da linguagem (imagem) existe ainda uma terceira coisa, que, produzida por essa relação, extrapola as significações convencionais. O texto de Manuel Bandeira dirige-se, portanto, a uma reflexão metalingüística, em que a discussão a respeito do fazer literário coincide com a própria produção desse fazer por meio da metáfora. Quanto a isso, acrescentamos a seguir o comentário de Lima (1987, p. 47):

A caracterização do texto moderno compreende, acima de tudo, a discussão em torno do fazer literário na atualidade. Para isso, concorre a aventura de, no próprio tecido poético, de natureza ficcional, utilizar-se o recurso da metalinguagem, que tanto se dá explicitamente, quanto implicitamente. No último caso - de relação mais sutil -, metáfora e metalinguagem coincidem, coexistem, pois o código, vivenciando um questionamento, é a própria mensagem, para utilizarmos os termos com que Roman Jakobson formulou as funções da linguagem com base nos elementos da comunicação.

A discussão metalingüística em "A realidade e a imagem" está no interior do processo de metaforicização. Com isso, a essência do poético é demonstrada através de seus próprios recursos, enfatizando a questão da representação, mas não tal qual o modelo tradicional em que o mimema equivale a uma pura imitação do objeto originário e sim como um duplo a incorporar a força produtiva da natureza. Costa Lima (1980,47), a esse respeito, comenta o seguinte:

Assim como a forma se realiza na concreção da matéria, assim a mímesis se cumpre na concreção de um mimema. Mais do que nunca, mímesis não pode ser tomada como imitatio. [...]. A mímesis é sinônimo de um campo fantasmal, é o outro da sombra, nem sequer a própria sombra, pois esta ainda supõe um corpo que a projeta. 
Desse modo, o arranha-céu do poema bandeiriano não equivale a nenhum edifício concreto na realidade, mas a uma criação que somente existe na língua e que serve como referência a diversos contextos e, principalmente, à discussão metalingüística. A metáfora no poema "A realidade e a imagem" redispõe o real, decompondo-o e construindo a partir dele novos significados para as coisas das quais ela se apropria mimeticamente. O arranha-céu desse poema rompe com a lógica positivista, possui algo de orgânico, de vivo, que extrapola as convenções imagísticas usuais. Descortina-se através das imagens desse poema a própria criação literária e um de seus elementos fundantes: a mímesis. Bandeira avalia a dicotomia existente entre a realidade e a sua transposição para a poesia.

Quanto a isso, Costa Lima (1995, p. 257-258) nos esclarece:

Não há discordância em se declarar que a mímesis se põe em ação movida por um desejo de semelhança. E não será preciso muita perspicácia para se entender que entre essa situação inicial e o resultado final a distância é (felizmente) imensa. [...]. Grosso modo, a mimesis implica um processo que, a partir,da busca de se tornar semelhante, dá lugar a dois resultados opostos. No primeiro caso, sua atividade interna converte a semelhança buscada em diferença alcançada. No segundo, socialmente mais freqüente, da busca de semelhança resulta um produto adaptado, a integração a um modelo de conduta e ação. [...]. Dentro desse segundo resultado ainda se distingue um caso extremo: aquele em que o processo da mímesis opera, por assim dizer, sem conversão interna, e à busca de semelhança corresponde a semelhança de fato alcançada. Só pois como anomalia a mímesis produz a cópia. Majoritariamente, ela enseja graus de diferença, sensivel no caso da mímesis ativa, por nuanças variáveis, no caso da passiva.

A realidade do poema existe por si mesma e não está necessariamente atrelada a um dado prévio, a uma realidade extratextual, mantendo com isso apenas uma relação de parecença com os possiveis modelos externos de que se utiliza. Bosi (2000, p. 20) aponta o seguinte a respeito disso: 
Formada, a imagem busca aprisionar a alteridade estranha das coisas e dos homens. [...]

A imagem, mental ou inscrita, entretém com o visivel uma dupla relação que os verbos aparecer e parecer ilustram cabalmente. O objeto dá-se, aparece, abre-se (latim: apparet) à visão, entrega-se a nós enquanto aparência: esta é a imago primordial que temos dele. Em seguida, com a reprodução da aparência, esta se parece com o que nos apareceu. Da aparência à parecença: momentos contíguos que a linguagem mantém próximos.

Desse modo, a imagem poética jamais retoma a coisa por ela referida, mas algo de sua alteridade, um elemento de sua composição que, sem deixar de se parecer com essa coisa, não é ela exatamente.

\section{Intensidade do feio e realidade destruída}

Passemos agora à leitura de mais um poema de Manuel Bandeira (1993, p. 136), intitulado de "Teresa":

A primeira vez que vi Teresa

Achei que ela tinha pernas estúpidas

Achei também que a cara parecia uma perna

Quando vi Teresa de novo

Achei que os olhos eram muito mais velhos que o resto do corpo

(Os olhos nasceram e ficaram dez anos esperando que o resto do corpo nascesse)

Da terceira vez não vi mais nada

Os céus se misturaram com a terra

E o espírito de Deus voltou a se mover sobre a face das águas.

Podemos facilmente constatar uma desvirtuação da imagem poética nesse texto: a caracterização da personagem adquire traços grotescos ("Achei que ela tinha pernas estúpidas"), numa visível demonstração de ataque às formas tradicionais de representação do belo. Nesse segundo verso da primeira estrofe do poema, fica caracterizado aquilo que Friedrich (1991, p. 77) identifica como intensidade do feio na poética da modernidade. Acerca disso, esse crítico assim comenta:

Belo e feio já não são valores opostos, mas digressões de estímulos. Sua diferença objetiva é eliminada, como a 
diferença entre verdadeiro e falso. A estreita aproximação do belo e do feio produz aquela dinâmica de contraste, que é o que importa. Porém esta deve também surgir a partir do próprio feio.

O feio, o esteticamente desagradável, passa a determinar a tensão poética, radicalizando por essa via a relação do texto com o seu leitor. Mais adiante, Friedrich (ibidem) examina o fundamental papel que tem a fealdade na poética moderna:

Uma poesia que toma por meta nos seus objetos menos os conteúdos que as relações de tensão sobre-objetiva necessita também do feio porque este, como provocação ao sentimento natural de beleza, produz aquela dramaticidade chocante que se deve estabelecer entre texto e leitor.

A intensidade do feio colabora no corpo do texto poćtico de Manuel Bandeira para uma gradativa imersão num contexto suprareal, para uma decomposição das formas sensiveis e uma conseqüente evasão para um vazio. Ao caracterizar de modo inusitado o semblante de sua musa ("Achei também que a cara parecia uma perna"), o poeta constrói uma imagem do feio que transcende um modelo convencional de feiúra. A esse respeito, Friedrich (ibidem, p. 79) acrescenta:

Querendo-se compará-lo com a feiúra, por assim dizer, normal, tornar-se-ia evidente que esta fealdade poética deforma também o feio real, assim como deforma tudo aquilo que é real para, no desmantelamento, tornar-se perceptível aquela evasão ao supra-real, que é, todavia, uma evasão ao vazio.

A musa a qual o poeta nomeia de Teresa é uma imagem deformada do próprio conceito de musa. Ela motiva a destruição da realidade ao redor do poeta, acarretando uma imersão no caos primordial, em que se acham as coisas num estado disforme ("Da terceira vez não vi mais nada / Os céus se misturaram com a terra / E o espírito de deus voltou a se mover sobre a face das águas"). A transcendência visualizada nas formas bizarras da musa acabam solapando a realidade. Trata-se, portanto, daquilo que Friedrich (1991, p. 76) denomina de realidade destruida, como ele próprio argumenta a esse respeito nessa passagem: 
[...] a paixão pela transcendência torna-se uma destruição cega da realidade. Esta realidade destruida constitui agora o sinal caótico da insuficiência do real em geral, como também da inacessibilidade do "desconhecido". Eis o que se pode chamar de dialética da modernidade.

Corresponde a esse processo de deformação do belo um processo equivalente ao nível da representação imagística do real. $\mathrm{O}$ elemento grotesco que compõe a figura de Teresa gera um desmantelamento radical da realidade, de modo que o mundo regride à caoticidade originária das coisas. Friedrich (ibidem) complementa-nos a seguir:

$\mathrm{Na}$ medida em que se pode dizer que ainda existe realidade (ou que podemos medir heuristicamente a poesia com base na realidade), esta é objeto de expansão, desmembramento, afeamento, tensões em contraste, a tal ponto que sempre vem a ser uma passagem ao irreal.

A imagem poética em "Teresa" conduz a um desfibramento do real, ocasionando por essa via uma fuga para a irrealidade.

\section{Magia da linguagem}

Um outro aspecto que gostariamos de ressaltar dentre os elementos da estrutura da lírica moderna presentes na obra de Manuel Bandeira é o que Friedrich (1991, p. 49) chama de magia da linguagem. A mímesis se deixa subjugar pelo despotismo de imagens extremamente acústicas, em que a combinação de determinadas vogais e consoantes cria um som tão forte que chega, em alguns casos, a obscurecer o seu significado. Podemos constatar esse aspecto da lírica moderna neste poema de Bandeira (1993, p. 158-159) denominado "Trem de Ferro":

Café com pão

Café com pão

Café com pão

Virge Maria que foi isso maquinista?

Agora sim

Café com pão

Agora sim 


\section{Voa, fumaça \\ Corre, cerca \\ Ai seu foguista \\ Bota fogo \\ $\mathrm{Na}$ fornalha \\ Que eu preciso \\ Muita força \\ Muita força \\ Muita força}

Ôิ...

Foge, bicho

Foge, povo

Passa ponte

Passa pasto

Passa boi

Passa boiada

Passa galho

De ingazeira

Debruçada

No riacho

Que vontade

De cantar!

Oô...

Quando me prendero

No canaviá

Cada pé de cana

Era um oficiá

Oô...

Menina bonita

Do vestido verde

Me dá tua boca

Pra matá minha sede

Oô...

Vou mimbora vou mimbora

Não gosto daqui

Nasci no sertão

Sou de Ouricuri

Oô...

Vou depressa

Vou correndo 


\section{Vou na toda \\ Que só levo \\ Pouca gente \\ Pouca gente \\ Pouca gente...}

Nesse poema, extraido do livro Estrela da manhã, há uma série de aliterações, anáforas e assonâncias que recriam mimeticamente o ritmo compassado de um trem a percorrer os trilhos de uma ferrovia. Ocorre um predomínio da sonoridade sobre o conteúdo nesse texto poético: sua estrutura nos mostra uma linguagem em que o material léxico, através de seus movimentos rítmicos, produz uma secundarização da mensagem em benefício da música. Friedrich (1991, p. 50) argumenta o seguinte:

[...] separam-se, na linguagem, a função de comunicação e a função de ser um organismo independente de campos de força musical. Mas a linguagem determina também o processo poético que se abandona aos impulsos ingênitos na própria linguagem. Descobre-se a possibilidade de criar um poema por meio de um processo combinatório que opere com os elementos sonoros e rítmicos da língua como com fórmulas mágicas. Seu significado surge não do esquema temático desta combinação - um significado oscilante, impreciso, cujo mistério ganha corpo não tanto pelas significações essenciais das palavras como por suas forças sonoras e marginalidades semânticas. Esta possibilidade se converte em praxe dominante na poesia moderna. O lírico se converte em mágico do som.

A quase ausência de pontuação nesse poema bandeiriano concede à cadência rítmica maior velocidade, gerando um poderoso efeito sonoro. $\mathrm{O}$ acento silábico geralmente recai $\mathrm{cm}$ palavras de natureza paroxítona, produzindo assim um compasso melódico bem marcado. O fôlego da enunciação marca a sua dinâmica musical. A esse respeito, Bosi $(2000$, p. 82) expõe:

Do fôlego dependem a intensidade e a aceleração do discurso.

Tais caracteres não são abstrações da Acústica. Na prática verbal, a força e o tempo servem a momentos de expressão em contextos significativos. Dizer com maior 
veemência uma determinada frase, ou certa parte desta, é exercer sobre a matéria sonora uma dose de energia que intenciona essa mesma matéria.

O poema incorpora mimeticamente a natureza do ritmo compassado do trem de ferro. O discurso poético, dessa forma, mescla elementos imagéticos do itinerário da ferrovia ("Passa pasto / Passa ponte / Passa boi / Passa boiada / Passa galho / De ingazeira / Debruçada / No riacho") à sonoridade que busca recuperar algo do movimento dos vagões. Bosi (idem) acrescenta:

A força e o tempo da prolação do enunciado são índices de uma situação semiológica que abraça o estado de alma do falante, a natureza da mensagem e o tipo de interlocutor.

No caso particular da dicção poética, os ritmos da fala são mantidos e potenciados.

A ordem objetiva, lógica e gramatical cede lugar às forças sonoras mágicas da lírica. O dizer poético assimila, inclusive, os traços característicos da fala popular cotidiana de comunidades interioranas às margens dos trilhos. Há um jogo lúdico com a musicalidade do léxico utilizado que visa mais do que simplesmente transmitir uma determinada mensagem, mas seduzir pelo encanto acústico das palavras.

\section{Conclusão}

A poética de Manuel Bandeira possui em seu processo de criação os mesmos elementos que caracterizam a estrutura da lírica moderna, conforme as concepções de Hugo Friedrich, tais como decomposição, fantasia ditatorial, intensidade do feio, realidade destruída e magia da linguagem.

O discurso poético bandeiriano reestrutura a reapresentação mimética dos objetos através de deslocamentos, recombinações, contrações e omissões que visam a uma fuga da realidade sensivel para uma atmosfera onírica, irreal. O poeta torna sensíveis imagens somente possíveis no contexto da linguagem.

Há, em certos momentos de sua poesia, uma ruptura com o esteticamente agradável, com o intuito de empregar o feio, ou o 
grotesco, como elemento dinamizador das tensões semânticas textuais. A evasão da realidade, que caracteriza a lirica bandeiriana e a moderna de modo geral, acarreta numa espécie de desrealização do real por meio do sonho, da decomposição das imagens e do despotismo da sonoridade das palavras.

Podemos, portanto, inferir que Manuel Bandeira conseguiu, através de seu olhar atento, captar as transformações por que passava a lírica de seu tempo e incorporá-las à sua forma peculiar de reapresentar as imagens do mundo.

\section{Referências}

ARISTÓTElES. Poética; Organon; Politica; a constituição de Atenas. São Paulo: Nova Cultural, 2000. (Col. Os pensadores)

BANDEIRA, Manuel. Estrela da vida inteira. Rio de Janeiro: Nova Fronteira, 1993.

BOSI, Alfredo. O ser e o tempo da poesia. São Paulo: Companhia das Letras, 2000.

COSTA LIMA, Luiz. Mimesis e modernidade: formas das sombras. Rio de Janeiro: Graal, 1980.

COSTA LIMA, Luiz. Vida e mímesis. Rio de Janeiro: Ed. 34, 1995.

FRIEDRICH, Hugo. Estrutura da lirica moderna: da metade do século XIX a meados do século XX. São Paulo: Duas Cidades, 1991.

LIMA, Roberto Sarmento. Manuel Bandeira: o mito revisitado: uma leitura intertextual da poética da modernidade. Rio de Janeiro: Tempo Brasileiro; Brasilia: Instituto Nacional do Livro, 1987. 